Pacific Journal of Mathematics

INFINITELY REPEATABLE GAMES 


\section{INFINITELY REPEATABLE GAMES}

\section{MELVIN KATZ}

1. Introduction. Blackwell [1] has introduced the concept of approachability in obtaining an analog of the von Neumann minimax theorem for games with vector payoffs. This paper continues the study of this concept. Games with vector payoffs are again two person decision problems with each player having $r$ and $s$ pure strategies respectively but the element of the payoff matrix corresponding to the $(i, j)$ strategy pair is a point $g(i, j)$ in Euclidean $N$-space. Let $C_{G}$ denote the convex hull of the rs points $g(i, j)$. Then the problem studied in approachability theory can be stated briefly as follows. If a game with vector payoffs is repeated in time can player I force the average payoff to approach a preassigned closed subset $S$ of $C_{G}$ with probability approaching 1 as the number of plays becomes infinite?

Because a sequence of games is being considered the rules of play must specify to what extent a player's decision at any stage may depend on past plays. This leads to the natural question of how the class of approachable sets depends on the type of information available to player I. It is specifically this question that is considered in this paper. The problem is formulated mere precisely below.

Let

$$
G=\|g(i, j)\|, \quad 1 \leqq i \leqq r, 1 \leqq j \leqq s
$$

be an $r \times s$ matrix each element of which is a point in Euclidean $N$-space and let

$$
\mathscr{J}=\left\|e_{(i, j), k}\right\|, \quad 1 \leqq i \leqq r, \quad 1 \leqq j \leqq s, \quad 1 \leqq k \leqq t
$$

denote an $r s \times t$ matrix such that $0 \leqq e_{(i, j)},{ }_{k}$ (for all $1 \leqq i \leqq r, 1 \leqq j \leqq s$, $1 \leqq k \leqq t$ ) and $\sum_{k=1}^{t} e_{(i, j), k}=1$ (for all $1 \leqq i \leqq r, 1 \leqq j \leqq s$ ). A pair $(G, \mathscr{J})$ will determine a game as follows. By a strategy for player $\mathrm{I}$ is meant a sequence $f=\left\{f_{n}: n=0,1,2, \cdots\right\}$ of functions where $f_{n}$, for $n=1,2, \cdots$, is a mapping from the set of $n$-tuples $\left(a_{1}, a_{2}\right.$, $\left.\cdots, a_{n}\right), a_{i} \in\{1,2, \cdots, t\}$, to the set $P=\left\{\left(p_{1}, \cdots, p_{r}\right) \mid 1 \leqq p_{i}, \sum_{1}^{r} p_{i}=1\right\}$, and $f_{0}$ is a point in $P$. A strategy for player II is a sequence of vectors $h=\left\{h_{n}: n=0,1,2, \cdots\right\}$ where $h_{n} \in Q=\left\{\left(q_{1}, \cdots, q_{s}\right) \mid 0 \leqq q_{j}, \sum_{1}^{s}\right.$

Received May 18, 1959. This paper was supported (in part) by funds provided under Contract AF(657)-29 with the School of Aviation Medicine, USAF, Randolph Air Force Base, Texas. Also the material of this paper is a slightly modified version of part of the author's doctoral thesis presented at the University of California, 1959. The author is indebted to Professor David Blackwell for his valuable suggestions and criticisms in supervising the thesis. 
$\left.q_{j}=1\right\}$ for $n=0,1,2, \cdots$. The interpretation of the play of the game $(G, \mathscr{J})$ is that player I selects a number, say $i_{1}$, from $\{1, \cdots, r\}$ according to the mixed strategy $f_{0}$ and player II selects a number, say $j_{1}$, from $\{1, \cdots, s\}$ according to the strategy $h_{0}$. The pair $\left(i_{1}, j_{1}\right)$ is observed by a referee who employs the distribution $\left\{e_{\left(i_{1}, j_{1}\right)}, \cdots, e_{\left(i_{1}, j_{1}\right), t}\right\}$ to choose a number, denoted $a_{1}$, from $\{1, \cdots, t\}$. The number $a_{1}$ is precisely the information told to player I at the conclusion of the first play of the game and he then chooses $i_{2}$ by means of the mixed strategy $f_{1}\left(a_{1}\right)$ while player II chooses $j_{2}$ with strategy $h_{1}$. The referee selects $a_{2}$ according to $\left.\left.\left\{e_{\left(i_{2}, j_{2}\right.}\right)_{1}, \cdots, e_{\left(i_{2}, j_{2}\right)}\right)_{t}\right\}$ and $a_{2}$ is told to player I who now employs a third mixed strategy $f_{2}\left(a_{1}, a_{2}\right)$ to choose $i_{3}$, etc. Thus a pair $(G, \mathscr{I})$ together with a fixed pair of strategies $(f, h)$ defines a vectorvalued stochastic process $\left\{Y_{n}: n=1,2, \cdots\right\}$ with $\left\{g_{\left(i_{n},{ }_{n}\right)}: n=1,2, \cdots\right\}$ being a realization of the process for a particular play of the game.

Let $C_{G}$ denote the convex hull of the $r s$ points $g(i, j)$ and let $S$ denote any closed set in $C_{G} . S$ is said to be approachable with $f^{*}$ in $(G, \mathscr{J})$ if for every $h$

$$
P\left\{\lim _{n} \delta_{n}=0\right\}=1
$$

where $\delta_{n}$ denotes the distance of the point $\sum_{1}^{n} Y_{i} / n$ from $S$ and $\left\{Y_{i}: i=\right.$ $1,2, \cdots\}$ is the vector-valued process determined by $f^{*}$ and $h$.

In $\S 2$ necessary and sufficient conditions are obtained for a set to be approachable when player I obtains no information concerning II's choices. In $\S 3$ sufficient conditions for approachability are given in the case when I knows nothing of his own past but is completely informed of II's past history. For convex $S$ the condition is both necessary and sufficient. Section 4 contains necessary and sufficient conditions for the approachability of convex $S$ in the case that the rank of $\mathscr{I}$ is equal to $r s$.

2. No information relevant to player II. It is clear that the minimal class of approachable sets is obtained when the rank of $\mathscr{F}$ is one (the case of no information) and the result of this section is that this class is made no larger if player I receives information concering only his own past play.

For any $p \in P$ denote by $R(p)$ the convex hull of the $s$ points $\sum_{i} p_{i} g_{i, j}$. It is an immediate consequence of the Strong Law of Large Numbers that $R(p)$ is approachable with the strategy $f^{*}=\left\{f_{n} \equiv p\right.$ : $n=0,1, \cdots\}$ and thus approachable in the case of $\operatorname{rank}(\mathscr{J})=1$. The theorem of this section is that the collection of $R(p)$ 's is essentially the totality to approachable sets when nothing is known concerning player II's past play. 
THEOREM 1. Let $\operatorname{rank}(\mathscr{F}) \leqq r$ and

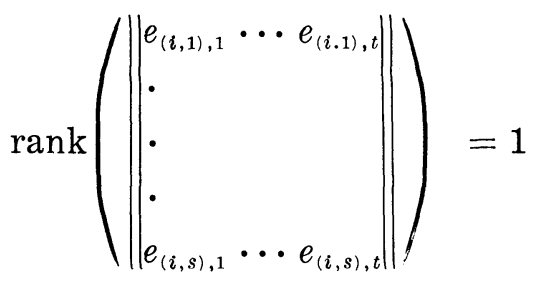

for $i=1, \cdots, r$. Then a closed set $S$ is approachable if and only if there exists $p \in P$ such that $R(p) \subseteq S$.

Proof. The sufficiency is an immediate consequence of the Strong Law of Large Numbers.

To prove the necessity of the condition suppose that $S$ is approachable. Let $f^{0}$ denote a strategy for player I with which $S$ is approachable. The strategy $f^{0}$ induces a vector-valued stochastic process $\left\{X_{n}=\right.$ $\left.\left(X_{1 n}, \cdots, X_{r n}\right): n=1,2, \cdots\right\}$ with

$$
X_{k n}= \begin{cases}1 & \text { if } i_{n}=k \\ 0 & \text { otherwise }\end{cases}
$$

for $k=1,2, \cdots, r ; n=1,2, \cdots$. Consider the process

$$
\left\{\bar{X}_{n}=\left(1 / n \sum_{i=1}^{n} X_{1 i}, \cdots, 1 / n \sum_{i=1}^{n} X_{r i}\right): n=1,2, \cdots\right\} ;
$$

it follows from Cantor's theorem that there exists $p_{0} \in P$ such that for any $\varepsilon>0$

$$
P\left\{d\left(\bar{X}_{n}, p_{0}\right)<\varepsilon i .0 .\right\}>0 \text {. }
$$

The proof will be completed by showing that $R\left(p_{0}\right) \subseteq S$.

Suppose $R\left(p_{0}\right) \nsubseteq S$, then there exists a positive number $\varepsilon_{0}$ and $q_{0} \in Q$ such that $C\left(z_{0}, \varepsilon_{0}\right)$, the sphere of radius $\varepsilon_{0}$ and center $z_{0}$ is disjoint from $S$ where $z_{0}=\sum_{i=1}^{r} \sum_{j=1}^{s} p_{i, 0} q_{j, 0} g_{i j}$ and $p_{0}=\left(p_{1,0}, \cdots, p_{r, 0}\right), q_{0}=\left(q_{1,0}, \cdots\right.$, $\left.q_{s, 0}\right)$. Let $h^{0}$ denote the strategy for player II defined by $h^{0}=\left\{h_{n}^{0} \equiv\right.$ $\left.q_{0}: n=0,1,2, \cdots\right\} . h^{0}$ induces a vector process $\left\{W_{n}=\left(W_{1 n}, \cdots, W_{s n}\right)\right.$ : $n=1,2, \cdots\}$ where

$$
W_{k n}=\left\{\begin{array}{ll}
1 & \text { if } j_{n}=k \\
0 & \text { otherwise }
\end{array} .\right.
$$

Now it is a consequence of the Strong Law of Large Numbers that for an arbitrary positive $\varepsilon$

$$
\begin{aligned}
P\left\{d \left[\left(\frac{1}{n} \sum_{i=1}^{n} X_{1 i} W_{1 i}, \frac{1}{n} \sum_{i=1}^{n} X_{2 i} W_{1 i}, \cdots, \frac{1}{n} \sum^{n} X_{r i} W_{s i}\right),\right.\right. \\
\left.\left.\left(p_{1,0} q_{1,0}, p_{2,0} q_{1,0}, \cdots, p_{r, 0} q_{s, 0}\right)\right]<\varepsilon i . o .\right\}>0 .
\end{aligned}
$$


Therefore,

$$
P\left\{\underline{\lim } d\left(\frac{1}{n} \sum_{1}^{n} Y_{i}, C\left(z_{0}, \varepsilon_{0}\right)\right)=0\right\}>0
$$

and thus $P\left\{\lim \delta_{n}=0\right\}<1$ where $\delta_{n}=d\left(1 / n \sum_{1}^{n} Y_{i}, S\right)$ and $\left\{Y_{i}:_{i}=\right.$ $1,2, \cdots\}$ is the vector-valued process determined by $f^{0}$ and $h^{0}$. Thus $R\left(p_{0}\right) \subseteq S$ and the proof is complete.

It is worthwhile to note that this theorem remains true if player II's class of strategies is restricted to strategies which are sequences of pure strategies, that is, if $h=\left\{h_{n}: n=0,1,2, \cdots,\right\}$ is a strategy for II, then all components of $h_{n}$ are zero with a single exception which is one. This restricted class of straregies for player II is essentially the smallest class for which the theorem remains true.

3. Complete information about player II. If player I is informed of the complete past history of player II's choice but receives no information concerning his own past play the class of approachable sets is greatly increased.

THEOREM 2 Let $\operatorname{rank}(\mathscr{I})=s$,

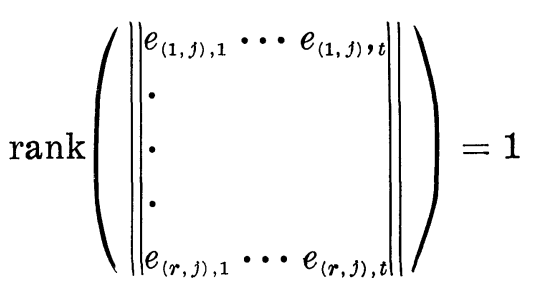

for $j=1,2, \cdots, s$ and finally assume $\sum_{k=1}^{t} e_{(i, j), k} e_{(u, v) k}=0$ for all $u \neq i$ and all $v$ and $j$. Then a closed set $S$ is approachable if for every $x \notin S, x \in C_{G}$, there exists $p \in P$ such that the plane through $y$, the closest point in $S$ to $x$, perpendicular to the line segment $x y$ separates $x$ from $R(p)$.

Proof. Let $S$ be an arbitrary closed set satisfying the hypothesis of the theorem. The proof consists in exhibiting a strategy $f^{*}$ for player I with which $S$ is approachable. By hypothesis if $x \notin S$ there exists at least one $p \in P$ such that $x$ is separated from $R(p)$; thus player I can associate a unique "separating $p$ " to each $x$, say $p(x)$. Further, because of the structure of $\mathscr{F}$ the sequences $\left\{a_{n}: n=1,2, \cdots\right\}$ and $\left\{j_{n}: n=1,2, \cdots\right\}$ may be identified and $f_{n}^{*}\left(j_{1}, \cdots, j_{n}\right)$ will be written for $f_{n}^{*}\left(a_{1}, \cdots, a_{n}\right)$.

The strategy $f^{*}$ for player $\mathrm{I}$ is now defined as follows:

$$
f_{0}^{*}=\left(\frac{1}{r}, \frac{1}{r}, \cdots, \frac{1}{r}\right)
$$




$$
f_{n}^{*}\left(j_{1}, \cdots, j_{n}\right)= \begin{cases}\left(\frac{1}{r}, \cdots, \frac{1}{r}\right) \text { if } \bar{z}_{n} \equiv \frac{1}{n} \sum_{1}^{n} r_{k} \in S \\ p\left(\bar{z}_{n}\right) \text { if } \bar{z}_{n} \notin S & n=1,2, \cdots\end{cases}
$$

where $z_{k}=\sum_{i=1}^{r} f_{k-1, i}^{*} g_{i j_{k}}$ and $f_{k}^{*}\left(j_{1}, \cdots, j_{k}\right) \equiv\left(f_{n, 1}^{*}, \cdots, f_{k, r}^{*}\right) k=0,1, \cdots$. To contruct $f_{n}^{*}\left(j_{1}, \cdots, j_{n}\right)$ player 1 has as information $\left(j_{1}, \cdots, j_{n}\right)$ and thus since a unique $p(x)$ has been associated to every $x \notin S$ it is possible for player I to reconstruct $f_{0}^{*}, \cdots, f_{n-1}^{*}$ and hence this strategy is well defined.

Let $\left\{Y_{n} \equiv\left(Y_{n, 1}, \cdots, Y_{n, N}\right) n=1,2, \cdots\right\}$ be the vector process generated by $f^{*}$ and some arbitrary strategy $h$ for player II. Then as mentioned previously $h$ generates a stochastic process $\left\{W_{n}: n=1,2, \cdots\right\}$. Denote by $w=\left(w_{1}, w_{2}, \cdots\right)$ an arbitrary sample sequence of this process. The proof will be completed if it is shown that $P\left\{\lim _{n}\right.$ $\left.d\left(1 / n \sum_{1}^{n} Y_{k}, S\right)=0 \mid w\right\}=1$ for arbitrary $w$.

Now note that for fixed $w$ the random variables $Y_{n, k}$ and $Y_{m, k}$ are stochastically independent for $n \neq m$ and $k=1,2, \cdots, N$ with mean values $z_{n, k}$ and $z_{m, k}$ respectively. Thus, it is an immediate consequence of the Strong Law of Large Numbers that it is sufficient to prove that $\lim d\left(\bar{z}_{n}, S\right)=0$ to complete the proof of the theorem.

Suppose $\bar{z}_{n} \notin S$ and let $u_{n}$ denote the point in $S$ closest to $\bar{z}_{n}$. Then $\left(u_{n}-\bar{z}_{n}, z_{n+1}\right) \geqq\left(u_{n}-\bar{z}_{n}, u_{n}\right)$ and if $\delta_{n} \equiv d^{2}\left(\bar{z}_{n}, S\right)>0$ it follows that $\delta_{n+1} \leqq\left|\bar{z}_{n+1}-u_{n}\right|^{2}=\left|\bar{z}_{n}-u_{n}\right|^{2}+2\left(\bar{z}_{n}-u_{n}, \bar{z}_{n+1}-\bar{z}_{n}\right)+\left|\bar{z}_{n+1}-\bar{z}_{n}\right|^{2}$.

However, $\bar{z}_{n+1}-\bar{z}_{n}=\left(z_{n+1}-\bar{z}_{n}\right) / n$ and thus,

$$
\left(\bar{z}_{n}-w_{n}, \bar{z}_{n+1}-\bar{z}_{n}\right)=\frac{\left(\bar{z}_{n}-u_{n}, z_{n+1}-u_{n}\right)+\left(\bar{z}_{n}-u_{n}, u_{n}-\bar{z}_{n}\right)}{n+1} .
$$

Further, $\left|\bar{z}_{n+2}-\bar{z}_{n}\right|^{2} \leqq A /(n+1)^{2}$, where $A$ is some constant, and thus if $\delta_{n-1}>0$ it follows that

(a) $\delta_{n} \leqq(1-2 / n) \delta_{n-1}+A / n^{2}$. Also since $C_{G}$ is bounded

(b) $0 \leqq \delta_{n} \leqq B$ and

(c) $\left|\delta_{n}-\delta_{n-1}\right| \leqq D / n$ where $B$ and $D$ are constants. However, if $\left\{\delta_{n}: n=1,2, \cdots\right\}$ is a sequence of real numbers satisfying (a), (b), and (c) it is quite easy to prove that $\lim _{n} \delta_{n}=0$. Thus the proof is complete.

Theorem 3. Let $T(q), q \in Q$, denote the convex hull of the $r$ points $\sum_{j=1}^{s} q_{j} g_{i j}$. Let. $\mathscr{T}$ satisfy the same conditions as in Theorem 2. Then a closed cenvex set $S$ is approachable if and only if it intersects every $T(q)$.

The proof of this theorem is given in $[\mathbf{1}]$ and will be omitted. 
4. rank $(\mathscr{I})=r s$. The theorem of this section was obtained in [1] for the case of $\mathscr{I}$ equal to the identity matrix.

Theorem 4. Suppose rank $(\mathscr{I})=r s$, then a closed convex set $S$ is approachable if and only if it intersects every $T(q)$.

Proof. The necessity is clear. If $S \cap T\left(q_{0}\right)$ is empty player II chooses $h^{0}=\left\{h_{n}^{0} \equiv q_{0}: n=0,1, \cdots\right\}$ and it is clear that $P\left\{\lim _{n} d\left(1 / n \sum_{1}^{n} Y_{k}, T\left(q_{0}\right)\right)\right.$ $=0\}=1$ where $\left\{Y_{k}: k=1,2, \cdots\right\}$ is generated by $h^{0}$ and any arbitrary strategy for player I. Thus since $S \cap T\left(q_{0}\right)$ is empty $S$ is not approachable.

Conversely let $S$ be an arbitrary closed convex subset of $C_{G}$ satisfying the hypothesis of the theorem. Define the $r \times s$ matrix $L=\left\|l_{\imath \jmath}\right\|$ as follows

$$
l_{i j}=\left(\delta_{1 i} \delta_{1 j}, \delta_{1 j} \delta_{2 i}, \cdots, \delta_{1 i} \delta_{s j}, \delta_{2 i} \delta_{1 j}, \cdots, \delta_{2 i} \delta_{s j}, \cdots, \delta_{r i} \delta_{1 j}, \cdots, \delta_{r i} \delta_{s j}\right) \in E^{r s}
$$

where $1 \leqq i \leqq r, 1 \leqq j \leqq s$, and $\delta_{u v}$ is the Kronecker delta. Define $S_{L}=$ $\left\{\sum_{i=1}^{r} \sum_{j=1}^{s} \alpha_{i j} l_{i j} \mid \sum_{i=1}^{r} \sum_{j=1}^{s} \alpha_{i j} g_{i j} \in S, 0 \leqq \alpha_{i j}\right.$ and $\left.\sum_{i=1}^{r} \sum_{j=1}^{s} \alpha_{i j}=1\right\}$, then $S_{L}$ is a closed convex subset of $C_{L}$ and $S_{L}$ intersects $T_{L}(q)$ for all $q \in Q$, where $T_{L}(q)$ is the convex hull of the $r$ points $\sum_{j=1}^{s} q_{j} l_{i j}$. Further, it follows after some simple computations that if $S_{L}$ is approachable in $(L, \mathscr{I})$ then $S$ is approachable in $(G, \mathscr{F})$ and in fact approachable with the same strategy. Thus to complete the proof of the theorem one need only show that every closed convex subset of $C_{L}$ is approachable in $(L, \mathscr{F})$ if it intersects $T_{L}(q)$ for all $q \in Q$.

Let $S$ be an arbitrary closed convex subset of $C_{L}$ and suppose $S \cap T_{L}(q)$ is nonempty for all $q \in Q$. Further, suppose $t=r s$ this can be done with no loss of generality. Define the matrix $L^{\prime}=$ $\left\|e_{(i, j)}\right\|(1 \leqq i \leqq r, 1 \leqq j \leqq s)$ where $e_{(i j)}$ denotes the probability distribution over $E^{r s}$ choosing $l_{11}$ with probability $e_{(i j), 1}, l_{12}$ with probability $e_{(i j), 2}, \cdots, l_{r s}$ with probability $e_{(i j), r s}$. Let $\bar{e}_{(i j)}$ denote the mean value of the distribution $e_{(i j)}$ and $\bar{L}^{\prime}$ denote the matrix of mean values, i.e., $\bar{L}^{\prime}=\left\|\bar{e}_{(i, j)}\right\|$. The if $f$ and $h$ denote respectively strategies for players I and II in the game $(L, \mathscr{J})$, the sequence $\left(a_{1}, a_{2}, \cdots\right)$ generated by $(f, h, L, \mathscr{I})$ may be taken to have been generated by $\left(f, h, L^{\prime}, \mathscr{I}^{0}\right)$ where $\mathscr{I}^{0}$ is the identity matrix. Finally define $S^{\prime}=\left\{\mathscr{J}^{T} s \mid s \in S\right\}$, where $\mathscr{I}^{T}$ denotes the transpose of $\mathscr{I}$; then $S^{\prime}$ is a closed convex subset of $C_{L}$ and further, $S^{\prime} \cap T_{\bar{L}},(q)$ is nonempty for all $q \in Q$. Thus, by the result of [1] $R^{\prime}$ is approachable in $\left(L^{\prime}, \mathscr{I}^{0}\right)$. Let $f^{0}$ denote a strategy for player I with which $S^{\prime}$ is approachable; the proof will be completed by showing that $S$ is approachable with $f^{0}$.

Let $h$ denote a strategy for player II. Let $\left\{Y_{n}: n=1,2, \cdots\right\}$ be the vector-valued process generated by $\left(f^{0}, h\right)$ in $L^{\prime}$ and let $\left\{U_{n}: n=\right.$ $1,2, \cdots\}$ be the process generated by $\left(f^{0}, h\right)$ in $L$. It remains to show 
that $P\left\{\lim _{n} d\left(\bar{U}_{n}, S\right)\right\}=1$. First note that $d\left(\bar{U}_{n}, S\right) \leqq d\left(\bar{U}_{n},\left(\mathscr{Y}^{T}\right)^{-1} \bar{Y}_{n}\right)$ $+d\left(\left(\mathscr{F}^{T}\right)^{-1} \bar{Y}_{n}, S\right)$; however, $d\left(\left(\mathscr{F}^{T}\right)^{-1} \bar{Y}_{n}, S\right)=d\left(\left(\mathscr{\gamma}^{r}\right)^{-1} \bar{Y}_{n},\left(\mathscr{F}^{T}\right)^{-1} S^{\prime}\right)$ $\left.\leqq \| \mathscr{I}^{T}\right)^{-1} \| d\left(\bar{Y}_{n}, S^{\prime}\right)$. Thus since $d\left(\bar{Y}_{n}, S^{\prime}\right) \rightarrow 0$ with probability one need only show that $d\left(\bar{U}_{n},\left(\mathscr{J}^{T}\right)^{-1} \bar{Y}_{n}\right) \rightarrow 0$ with probability one to be done. However, $d\left(\bar{U}_{n},\left(\mathscr{I}^{T}\right)^{-1} \bar{Y}_{n}\right) \leqq\left\|\mathscr{F}^{T}\right\| d\left(\bar{Y}_{n},\left(\mathscr{F}^{T}\right) \bar{U}_{n}\right)$ and an immediate application of the Stability Theorem [2, p. 387] shows that $d\left(Y_{n},\left(\mathscr{I}^{T}\right) U_{n}\right)$ $\rightarrow 0$ with probability one; this completes the proof.

\section{REFERENCES}

1. David Blackwell, An analog of the minimax theorem for vector payoffs, Pacific J. Math., 6 (1956), 1-8.

2. Michel Loève, Probability Theory, van Nostrand, New York, 1955.

UNIVERSITY OF CHICAGO 



\section{PACIFIC JOURNAL OF MATHEMATICS}

\section{EDITORS}

\author{
David Gilbarg \\ Stanford University \\ Stanford, California \\ F. H. Brownell \\ University of Washington \\ Seattle 5 , Washington
}

\author{
A. L. Whiteman \\ University of Southern California \\ Los Angeles 7, California \\ L. J. PAIGE \\ University of California \\ Los Angeles 24, California
}

\section{ASSOCIATE EDITORS}

\author{
E. F. BECKENBACH \\ T. M. CHERRY \\ D. DERRY
}
E. HEWITT
A. HORN
L. NACHBIN
M. OHTSUKA
H. L. ROYDEN
M. M. SCHIFFER

E. SPANIER

E. G. STRAUS

F. WOLF

\section{SUPPORTING INSTITUTIONS}

\author{
UNIVERSITY OF BRITISH COLUMBIA \\ CALIFORNIA INSTITUTE OF TECHNOLOGY \\ UNIVERSITY OF CALIFORNIA \\ MONTANA STATE UNIVERSITY \\ UNIVERSITY OF NEVADA \\ NEW MEXICO STATE UNIVERSITY \\ OREGON STATE COLLEGE \\ UNIVERSITY OF OREGON \\ OSAKA UNIVERSITY \\ UNIVERSITY OF SOUTHERN CALIFORNIA
}

\author{
STANFORD UNIVERSITY \\ UNIVERSITY OF TOKYO \\ UNIVERSITY OF UTAH \\ WASHINGTON STATE COLLEGE \\ UNIVERSITY OF WASHINGTON

AMERICAN MATHEMATICAL SOCIETY
CALIFORNIA RESEARCH CORPORATION
HUGHES AIRCRAFT COMPANY
SPACE TECHNOLOGY LABORATORIES
NAVAL ORDNANCE TEST STATION

Mathematical papers intended for publication in the Pacific Journal of Mathematics should be typewritten (double spaced), and the author should keep a complete copy. Manuscripts may be sent to any one of the four editors. All other communications to the editors should be addressed to the managing editor, L. J. Paige at the University of California, Los Angeles 24, California. ..

50 reprints per author of each article are furnished free of charge; additional copies may be obtained at cost in multiples of 50 .

The Pacific Journal of Mathematics is published quarterly, in March, June, September, and December. The price per volume (4 numbers) is $\$ 12.00$; single issues, $\$ 3.50$. Back numbers are available. Special price to individual faculty members of supporting institutions and to individual members of the American Mathematical Society: $\$ 4.00$ per volume; single issues, $\$ 1.25$.

Subscriptions, orders for back numbers, and changes of address should be sent to Pacific Journal of Mathematics, 2120 Oxford Street, Berkeley 4, California.

Printed at Kokusai Bunken Insatsusha (International Academic Printing Co., Ltd.), No. $6_{4}$ 2-chome, Fujimi-cho, Chiyoda-ku, Tokyo, Japan.

PUBLISHED BY PACIFIC JOURNAL OF MATHEMATICS, A NON-PROFIT CORPORATION

The Supporting Institutions listed above contribute to the cost of publication of this Journăl, but they are not owners or publishers and have no responsibility for its content or policies. 


\section{Pacific Journal of Mathematics}

\section{Vol. 10, No. $3 \quad$ November, 1960}

Glen Earl Baxter, An analytic problem whose solution follows from a simple

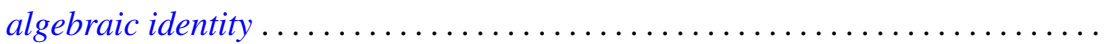

Leonard D. Berkovitz and Melvin Dresher, A multimove infinite game with linear payoff. .

Earl Robert Berkson, Sequel to a paper of A. E. Taylor ......................

Gerald Berman and Robert Jerome Silverman, Embedding of algebraic systems.... 767

Peter Crawley, Lattices whose congruences form a boolean algebra . . . . . ...... 777

Robert E. Edwards, Integral bases in inductive limit spaces . . . . . . . . . . . . . . .

Daniel T. Finkbeiner, II, Irreducible congruence relations on lattices . . . . . . . . . .

William James Firey, Isoperimetric ratios of Reuleaux polygons . . . . . . . . . . . 787

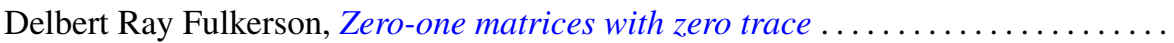

Leon W. Green, A sphere characterization related to Blaschke's conjecture........

Israel (Yitzchak) Nathan Herstein and Erwin Kleinfeld, Lie mappings in

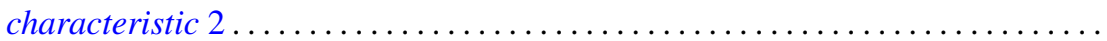

Charles Ray Hobby, A characteristic subgroup of a $p$-group .................

R. K. Juberg, On the Dirichlet problem for certain higher order parabolic

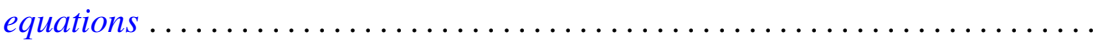

Melvin Katz, Infinitely repeatable games ......................

Emma Lehmer, On Jacobi functions . . . . . . . . . . . . . . . . . . . . . . . . .

D. H. Lehmer, Power character matrices

Henry B. Mann, A refinement of the fundamental theorem on the density of the sum of two sets of integers.

Marvin David Marcus and Roy Westwick, Linear maps on skew symmetric matrices: the invariance of elementary symmetric functions . .

Richard Dean Mayer and Richard Scott Pierce, Boolean algebras with ordered

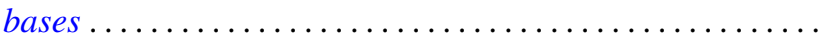

Trevor James McMinn, On the line segments of a convex surface in $E_{3} \ldots$

Frank Albert Raymond, The end point compactification of manifolds ..

Edgar Reich and S. E. Warschawski, On canonical conformal maps of regions of arbitrary connectivity

Marvin Rosenblum, The absolute continuity of Toeplitz's matrices...

Lee Albert Rubel, Maximal means and Tauberian theorems . .

Helmut Heinrich Schaefer, Some spectral properties of positive linear operators

Jeremiah Milton Stark, Minimum problems in the theory of pseudo-conformal transformations and their application to estimation of the curvature of the invariant metric.

Robert Steinberg, The simplicity of certain groups ...

Hisahiro Tamano, On paracompactness. .

Angus E. Taylor, Mittag-Leffler expansions and spectral theory .

Marion Franklin Tinsley, Permanents of cyclic matrices ...... . 